\title{
Fedro e a fábula coliâmbica de Catulo
}

\author{
Gabriel Castilho de Andrade Gil \\ Doutorando - Universidade Federal de Minas Gerais (UFMG) \\ gabrielcastilhogil@gmail.com
}

\begin{abstract}
RESUMO: O objetivo deste trabalho é cotejar aspectos da poesia de Fedro (I d.C.) e do poema 22 de Catulo (87-57 a.C.), à luz das relações que os dois poetas latinos estabelecem com a poesia coliâmbica grega pregressa. Para isso, realiza-se, previamente, um breve levantamento de características presentes na obra coliâmbica remanescente dos poetas Hipônax (VI a.C.) e Calímaco (310-240 a.C.) que encontram correspondência com elementos da obra de Fedro. $\mathrm{O}$ fabulista Fedro, ao contrário de Catulo, escreveu unicamente em senários iâmbicos, mas tal opção métrica, como evidencia-se, não o impediu de experimentar importantes estratégias criativas também encontradas entre os poetas coliâmbicos. Destaca-se, nesse sentido, que tanto Fedro quanto Catulo dão prosseguimento ao precedente calimaquiano de tornar os poemas suportes para a crítica estética, a partir do emprego da fábula.
\end{abstract}

Palavras-chave: Fedro, Catulo, Calímaco, fábula esópica, poesia coliâmbica

\section{Phaedrus and Catullus' choliambic fable}

\begin{abstract}
The aim of this paper is to compare some features of Phaedrus' poetry (I CE) to those of Catullus, 22. I managed to make such comparisons in the light of the relations set between these two Latin poets and former Greek choliambic poetry. In order to do so, I have previously performed a brief survey regarding those poetic features found in the extant choliambic works of Hipponax (VI CE) and Callimachus (310-240 BCE) which, accordingly, match Phaedrus' poems' features. Phaedrus, the fabulist, unlike Catullus, wrote solely in iambic senarius. However, as I present here, this choice did not hinder Phaedrus from following meaningful creative techniques witch which some of the choliambic poets also experimented. One must stress, thereupon, that both Phaedrus and Catullus resumed the Callimachean trace of turning poems into frames for aesthetic criticism by making use of Aesopic fables.
\end{abstract}

Keywords: Phaedrus, Catullus, Calimachus, aesopic fable, choliambic poetry. 


\section{Introdução ${ }^{1}$}

A distância estimada que separa as vidas dos poetas Catulo (87 - 54 a.C.) e Fedro (I d.C.) abarca, sobretudo, as mais lembradas manifestações remissivas à poesia calimaquiana em Roma. É em ampla porção desse intervalo que se desenvolvem por completo as obras de Virgílio, Horácio, Propércio, Tibulo e Ovídio. Com esses poetas, a poesia romana experimenta uma série de transformações balizadas pelos recorrentes parâmetros da variedade (formal ou temática), da brevidade (ou antes, da indisposição com as longas expressões da epopeia), da pungente erudição das bibliotecas, entre outros, consagrados pelo poeta Calímaco (310 - 240 a.C.) e alguns de seus contemporâneos.

O marco de Catulo, ou, com maior justiça, dos líricos da geração de Catulo, pode eventualmente trazer algo de elusivo, pois poetas anteriores já teriam, sim, conhecido e experimentado estratégias conscientemente calimaquianas. À guisa de exemplo está a hipótese, conveniente para este trabalho, de que o próprio poeta Ênio (239-169 a.C.) teria em mente certa correspondência entre as suas Saturae e os Iamboi de Calímaco (RUSSO, 2001, p. 100). Entretanto, o desenvolvimento de uma lírica propriamente romana, amplamente polimétrica e rigorosa em preceitos compositivos como os do "esforço", da "brevidade" e de certa "originalidade" é, documentalmente, distinto em Catulo.

Ao momento da produção fedriana, é possível dizer que o calimaquianismo já possui pleno desenvolvimento em Roma e que um certo distanciamento crítico de seus imperativos criativos já é uma característica bem desenhada em alguns autores ${ }^{2}$. O poeta Pérsio, por exemplo, em um prólogo, no qual se reconhece apenas parcialmente como sendo da comunidade dos vates (Pers. Pr., 6-7), não poupa críticas aos poetas de derivação calimaquiana e os identifica como papagaios (psitacco - v. 8) e tagarelas (picam - v. 9). Fedro, ao longo dos cinco livros de seu fabulário, nunca será mordaz como Pérsio, mas sua presença na tradição calimaquiana - que não poderemos explorar com grande afinco neste trabalho - decerto extrapola o legado catuliano dessa tradição helenística; tal legado, por sua vez, é perceptível e declarado em Fedro já no primeiro poema de seu fabulário (Ph. 1. Pr., 1): Esopo é o autor que inventou a matéria;/ esta, eu poli em versos senários ${ }^{3}$.

\footnotetext{
${ }^{1}$ Agradeço pelos pareceres da revista Rónai, pelos comentários e sugestões, que acatei com satisfação. O presente trabalho foi realizado com apoio da Coordenação de Aperfeiçoamento de Pessoal de Nível Superior - Brasil (CAPES) - Código de Financiamento 001.

${ }^{2}$ A paródia de elementos e opções calimaquianas - ainda que a voz poética paródica não se exclua do legado de Calímaco - é um traço que desponta já nos Anais do poeta Ênio e que emergirá em outras ocasiões, na poesia de Horácio e de Ovídio, por exemplo. Sua grande difusão, contudo, é a partir do século I d.C. (GLAUTHIER, 2009, pp. 272-3).

3 Tradução e grifos de nossa responsabilidade, a partir de: Aesopus auctor quam materiam repperit,/Hanc Ego poliui uersibus senariis. (FEDRO, Fab., Pr., 1-2). Os textos latinos de Fedro são tomados a partir da edição de Ben Edwin Perry (1965).
} 
Chama-nos atenção que a relação estabelecida entre o poeta Fedro e suas fábulas se identifique com um procedimento técnico exercido sobre as fábulas de seu precursor Esopo: poliui. É costumeira a aproximação entre Fedro e Horácio justamente pela formalização didática que o poeta venusino oferece ao parâmetro criativo: é o labor limae (Hor. Ars P., 291) que, também aqui, orienta o trabalho criativo de Fedro. Contudo, cumpre reconhecer que a formulação poética expressa por Fedro está mais próxima da de Catulo (Catul., 1, 1-2): "A quem darei meu lépido livrinho novo/ recém-polido à pome áspera?" 4 . Para além da morfologia lexical, os dois termos, expolitum e poliui, encontram-se em posições próximas: no segundo verso do primeiro poema de suas respectivas antologias. Este detalhe, por si só, basta como sinalização à herança partilhada da argupníe (ou pónos), o trabalho criativo incansável e insone, de Calímaco.

Reiterada a evidência de proximidades, devemos nos direcionar para um outro ponto de contato menos comentado entre os dois poetas e que é parcialmente salientado pelo restante do segundo verso de Fedro. $O$ único detalhamento acerca do polimento que o fabulista pretende oferecer à sua matéria é o da forma jâmbica: uersiis senariis, a formulação métrica que se consolida em Roma como própria aos diálogos das comédias e tragédias. Fedro se beneficia da estrutura dialógica como um elemento comum entre fábula e comédia para afirmar sua relação com o senário iâmbico. Catulo, por outro lado, incluirá os senários (ou trímetros) ${ }^{5}$ iâmbicos entre seus poemas em algumas ocasiões, mas o intuito deste poeta no emprego do senário jâmbico passa, antes, por um espírito restaurador frente às liberdades com que os comediógrafos romanos, como Plauto e Terêncio, haviam utilizado o verso, herdado da cultura literária grega (MORGAN, 2010, p. 116). Devemos reconhecer que, apesar do rigor calimaquiano, Fedro não parece ter qualquer propósito de "purificar" seu senário iâmbico e, paralelamente, Catulo não explora essa formulação métrica como o ambiente ajustado à sua única fábula.

A proximidade entre Fedro e Catulo que interessa a este trabalho deve ser buscada em ambientes poéticos distintos explorados pelos dois autores. $\mathrm{O}$ fato

\footnotetext{
${ }^{4}$ Tradução e grifos de nossa responsabilidade, a partir de: Cui dono lepidum nouum libellum/Arida modo pumice expolitum? (CATULO, 1,1-2). Os textos latinos de Catulo são tomados a partir da edição elaborada por D.F.C. Thomson, publicada em 1997.

${ }^{5}$ Uma real distinção entre o trímetro (normalmente associado à poesia grega) e o senário (associado à poesia latina) nem sempre é observada pelos próprios comentadores antigos, como Horácio (Hor. Ars P., 251-253) ou Quintiliano (Quint. Inst. 9, 4, 74), que defendem certa intercambialidade entre as duas nomenclaturas. Cada uma parece motivada por uma concepção diferente do que determina a unidade métrica do verso. O senário iâmbico é constituído por seis (de onde "senário") pés "potencialmente" iâmbicos (x -, o último pé, contudo, é obrigatoriamente iâmbico), já que a metrificação latina permite maior uso do anceps (sílaba facultativa entre breve ou longa) ao longo dos cinco primeiros pés. A suposta inexistência dessa liberdade na metrificação grega cria três blocos (métron) de quatro sílabas, ou dois pés, sendo o segundo pé dessa dipodia obrigatoriamente iâmbico $(|\mathrm{x}-\mathrm{u}-|)$. Sobre as nuances dessas duas formas na literatura latina, cf. o capítulo 3.3 da tese de doutoramento de Beethoven Alvarez (2016).
} 
de a única inquestionável fábula de Catulo aparecer em um poema coliâmbico (Catul. 22) - forma que também poderíamos considerar "desviante" do trímetro/senário iâmbico tradicional - tem relevância inquestionável e não deve ser considerado um empecilho num cotejo com a poesia fedriana. Com efeito, acreditamos poder elucidar que certas características encontradas em poetas coliâmbicos anteriores a Catulo e também em Fedro permitem o estabelecimento de um diálogo consistente entre aspectos da poesia coliâmbica de Catulo e da fábula iâmbica de Fedro. Essa estratégia, defendemos, também será capaz de indicar um aspecto do calimaquianismo que incide com destacada particularidade em Catulo e Fedro.

\section{Fedro e o coliambo grego: Hipônax e Calímaco}

O coliambo é o nome dado à disposição do verso trímetro iâmbico em que o último pé métrico é formado por um espondeu (- -) ou um troqueu $(-U)$, o que inverte a sequência costumeira de sílaba breve e sílaba longa (do trímetro iâmbico) e cria um efeito identificado com a própria alcunha de "iambo manco", que traduz a expressão geratriz grega "chōlós" (manco) + "íambos" (iambo). A forma coliâmbica é primeiramente associada à brutalidade característica da poesia legada pelo seu provável criador, Hipônax de Éfeso (VI. a. C), o mais recente dos três iambógrafos eleitos pelo cânone helenístico. $\mathrm{O}$ poeta em questão é autor de versos extremamente agressivos, invectivas comumente (pelo que indicam os pequenos fragmentos) dirigidos ao escultor Búpalo ${ }^{6}$ que o havia caricaturizado, e a mulheres em geral. ${ }^{7}$

A associação entre o coliambo e a violência levou o retor Demétrio (III-II a.C.), em sua obra Sobre o Estilo (Demetr., Eloc., 301), a se aprofundar nos condicionadores formais dessa disposição poética:

E, como a figura da disjunção produz veemência, conforme dito anteriormente, irá produzi-la a composição toda repleta de disjunções. Prova disso é uma passagem de Hipónax: querendo, pois, injuriar os inimigos, ele quebrou o metro e o tornou manco, ao invés do correto, e sem ritmo, isto é, conveniente à veemência e à injúria. Afinal, aquilo que contém ritmo e é eufônico conviria mais aos encômios do que às reprovações. (FREITAS, 2011, p. LXIV).

É assaz problemático elencar características indiscutivelmente hiponacteanas nas fábulas fedrianas diante do estado fragmentário da obra do poeta arcaico. Algumas possibilidades, contudo, podem ser aventadas.

\footnotetext{
${ }^{6}$ Hippon. 12, 84, 95a West.

${ }^{7}$ Hippon. 68 West.
} 
Encontramos nos poemas de Hipônax linguagem grotesca 8 , ocasionalmente erótica, mais explícita do que a encontrada nos dois iambógrafos que o antecedem ${ }^{9}$. A poesia de Fedro contém invectivas, mas nunca com a rispidez e o vocabulário virulento de Hipônax; a agressividade não é um traço muito saliente na poesia de Fedro. Em uma fábula como "O eunuco ao ímprobo" (Ph. 3.11), poderíamos esperar abuso e chacota graficamente expressos, num eventual tratamento por Hipônax. Em Fedro, por outro lado, a narrativa descreve de modo distante os sofrimentos que o eunuco sofre de seu abusador e dispõe em discurso direto uma réplica elegante, bem-humorada e perspicaz ${ }^{10}$.

Encontramos no fabulista, com certa frequência, alguma invectiva de natureza marcantemente misógina, como na fábula $P h$. App. 15, em que a personagem de Esopo critica a vaidade de sua domina, ou na fábula 2.2, em que um homem tem seus cabelos pretos arrancados por uma amante velha e os cabelos grisalhos por uma amante jovem.

De toda maneira, a direção de duras críticas em tom quase gnômico a mulheres é uma característica que está bem representada, também, desde Hesíodo e a poesia iâmbica arcaica do pouco conhecido Semônides de Amorgos (VII a.C.), poeta anterior a Hipônax. Ademais, atravessa a literatura antiga em inúmeras ocasiões e não deve ser considerado o traço distintivo de uma derivação em Fedro'1.

Algumas tentativas de sugerir uma relação entre baixa estima social e locução de fábulas foram realizadas ${ }^{12}$, mas Hipônax não contribui para essa correlação; apesar da persistente autocaracterização poética como um indivíduo pobre $^{13}$, a ponto de lhe faltarem recursos básicos para enfrentar o frio ${ }^{14}$, nenhuma alusão a fábulas subsiste nos seus fragmentos ${ }^{15}$. Um imaginário animal também

\footnotetext{
${ }^{8}$ Hippon. 73, 78, 92 West.

${ }^{9}$ Hippon. 84 West.

10 “'Eis', diz o eunuco, 'É apenas por isso, porque sofro tenazmente,/ porque me faltam os testigos de minha integridade/ mas por que, Tolo, me acusas de um delito da fortuna?/ Enfim, [só] é vergonhoso ao homem aquilo que mereceu sofrer."' - Tradução nossa a partir de: En 'ait' hoc unum est cur laborem ualidius,/ integritatis testes quia desunt mihi./ sed quid Fortunae, stulte, delictum arguis?/ id demum est homini turpe quod meruit pati (FEDRO, Fab. 3.11, 4-7).

11 Além dos dois exemplos supramencionados, poderíamos incluir: Ph. App.11 ("Juno, Vênus e a galinha"), sobre avidez sexual feminina; Ph. App.4 ("Mercúrio e as duas mulheres"), sobre desejos insensatos; Ph. App.29 (“A prostituta e o jovem"), sobre infidelidade. (cf. ADRADOS, 1979, p. 640).

12 Cf. JORDAN, 2013.

13 Hippon. 36, 38, 39, 40, 79 West.

14 Hippon. 32 West.

15 Se considerarmos que a fábula é um elemento presente e bem integrado à poesia do iambógrafo Arquíloco de Paros, e que subsiste ao menos como alusão na poesia de Semônides de Amorgos, é de se suspeitar que ela também tenha sido poeticamente trabalhada por Hipônax. Entretanto, não se deve fazer dessa conjectura uma tentativa de equivaler aspectos nas obras dos três iambógrafos arcaicos. No mais posterior dos três, como relembra Carey, não há engajamento político, como há na poesia dos dois iambógrafos anteriores (CAREY, 2009, p. 162-3). Não encontramos em Hipônax outras características, como o senso de integração a uma comunidade e seu policiamento moral. A autopercepção hiponacteana, como também reforça o comentador, parece alinhá-lo mais com os líricos do século VI a.C. (CAREY, 2009, p. 165).
} 
não é tão recorrente ${ }^{16}$. A despeito da sugestão manuscrita de que Fedro fosse um escravo, a autocaracterização fedriana não procura se ligar diretamente à pobreza. Independentemente, a autoconsciência é um traço que conecta Fedro a Hipônax e que não é encontrada com tal expressividade nos iâmbicos mais antigos ${ }^{17}$.

De forma oposta, a poesia coliâmbica de Calímaco, apesar de fragmentária, permite-nos reconhecer que já não está presente a truculência invectiva de Hipônax, ainda que a invectiva, em si, seja prevista como componente iâmbico; o iambo do Hipônax calimaquiano apenas não mais cantará a batalha com o escultor Búpalo (Call. Iamb. I, 10-11). Em contrapartida, a fábula, que, como comentamos acima, não foi preservada em nenhum fragmento de Hipônax, é retomada em pelo menos duas ocasiões dos iambos de Calímaco, com uma significativa expansão e reformulação das características identificáveis nos poucos exemplos restantes da poesia iâmbica arcaica.

O próprio Esopo, em si, segundo Benjamin Acosta-Hughes, pode ter interessado a Calímaco por uma variedade de características que acabaram sendo replicadas ao longo dos 13 Iambi (ACOSTA-HUGHES, 2002, p. 173). Esse é o caso da figura do sábio itinerante (presente no iambo 1) que vive em situação humilde, sem posses, mas sempre virtuosamente (presente no iambo 3) e que é, porventura, recebido negativamente pelos seus críticos (como acontece tanto no iambo 1 quanto no iambo 13 e, em um sentido particular, no iambo 2, também). Essas segundo o crítico, se tornam, fundamentalmente, características das personae poéticas exploradas ao longo da obra. Calímaco, então, incorpora muito mais do que apenas a fábula, mas uma série de elementos sobre a tradição fabular e o próprio Esopo.

O fabulário de Fedro deve muito aos coliambos de Calímaco pela preocupação em incorporar, de modos particulares aos propósitos do fabulista, aspectos que o poeta helenista valoriza na sua percepção da figura de Esopo. Fedro associa à figura de Esopo simplicidade, sabedoria e virtude, e ainda tem oportunidade de explorar outras qualidades por uma ostensiva frequência de representação. Se Calímaco o menciona ao menos uma vez nos seus Iambi, o iambo 2, no contexto lendário da passagem de Esopo pela cidade de Delfos, que resultaria em sua morte, Fedro, por sua vez, introduz a figura de Esopo em não menos que 24 textos, entre fábulas e editoriais ${ }^{18}$.

\footnotetext{
${ }^{16}$ Cf. Hippon. 54 West (sobre a coruja), 66 West (símile com o cão traiçoeiro), 115 West, v.11 (comparação com um cão).

${ }^{17}$ Apesar da situação fragmentária da obra de Hipônax, a recorrência do seu nome é interpretada por Brown (1997, p. 80) nesse sentido.

${ }^{18}$ Entre os textos preservados no fabulário, há sete menções a Esopo enquanto um autor de uma tradição (Ph. 1. Pr.; 1.3; 2. Ep. 3. Pr.; 4.7; 4.22; 5. Pr.); três em que ele identifica uma tipologia literária (Ph. 1.10; 2. Pr.; 4. Pr); quatro em que ele é personagem-narrador (Ph. 1.2; 1.6; 4.18; App.10) e dez
} 
Curiosamente, a querela entre Esopo e a população de Delfos não é abordada em nenhuma fábula fedriana, de modo que o ensejo para comentar a respeito da má recepção de algum poema, postura poética, ou mesmo da severidade dos críticos, será encontrado sobretudo nos editoriais do seu fabulário. Sendo assim, o próprio Fedro, à maneira de Hipônax, no iambo I; de Esopo, no iambo 2; e da persona poética de Calímaco, no iambo 13, é alvo dessas posturas e as comenta performando uma longa batalha discursiva contra uma entidade a que Calímaco dará verdadeira personalidade literária, o liuor, a inveja dos críticos ${ }^{19}$.

Os iambos calimaquianos 2 e 4 também nos chamam atenção, sobretudo por conterem, cada um, uma fábula. O estatuto de ambas é fragmentário, mas permite entrever que um tipo específico de crítica é desenvolvido a partir da natureza comunicacional das personagens envolvidas.

Na primeira das duas fábulas - presente no iambo 2 -, cuja narrativa íntegra também não foi preservada em outras fontes, há uma comparação explícita entre os tragediógrafos e os peixes, e há um palpite - oferecido por um suplemento crítico presente na Diegese dos Iambi 20 - de que a voz de algum indivíduo não preservado no fragmento, semelhante à de um papagaio (psittakoû - v. 11), seria referente aos oradores (rhētẽres - v. 11). Acompanhando-se tais sugestões, não se deve afastar a possibilidade de que Calímaco esteja empregando a fábula como suporte para a polêmica literária e, ao menos nesses dois exemplos, tecendo, literariamente, comentários a dois gêneros cujo estatuto no período não é tão bem conhecido: a oratória e a tragédia. Benjamin AcostaHughes afirma que há inovação no uso calimaquiano da fábula justamente pela instrumentalização do gênero enquanto modo de expressão de comentários poéticos e pela sua inserção entre as ferramentas críticas eruditas ao alcance do próprio academicismo helenista (ACOSTA-HUGHES, 2002, p. 174, 178).

Encontraremos essa elevação da fábula, inclusive para o debate de formas literárias consideradas mais prestigiadas do que ela, também, no iambo 4, que serve de plataforma para uma adaptação monumental, de aproximadamente 90 versos, da fábula "O Loureiro e a Oliveira" 21. Há muitas incertezas sobre as identidades alegóricas que constituem a fábula, mas se seguirmos a interpretação

em que ele é personagem do ágon da fábula (Ph. 2.3; 3.3; 3.5; 3.14; 3.19; 4.5; App.7; App.11; App.15; App.18).

19 O paradigma acerca da inveja (o Phthónos calimaquiano) e a crítica (Mómos) é pervasivamente incorporado à literatura latina: Horácio (Hor. Sat. 1.10, 2.1); Ovídio, (Ov. Am., 1.15; Pont., 4.16) são alguns exemplos. 0 modelo romano parece bem representado no poema de Calímaco, em Hino a Apolo (Call. Hymnus in Apollinem Cer. 2.105-113).

20 Tal como registrada em sua edição de Calímaco elaborada por Constantinos Trypanis (CALÍMACO, 1975 , p. 114)

${ }^{21}$ Não há uma fábula como essa entre as coleções anônimas, apesar de que possa haver alguma relação entre ela e a fábula "A macieira e o pé de romã" (213 Perry). De todo modo, contendas opondo personagens não são incomuns entre as fábulas anônimas. 
de Ruth Scodel e Benjamin Acosta-Hughes de que a rivalidade entre Calímaco e seu opositor só poderia ser literária, é tentador acreditar que as duas personagens vegetais da fábula estivessem simulando, metaforicamente, oposições entre diferentes poetas, ou gêneros poéticos ${ }^{22}$. (ACOSTA-HUGHES, 2002, p. 191; SCODEL, 2011, p. 376).

A consciência crítica de Fedro, como apontado anteriormente, está muito bem sinalizada nos editoriais ao fabulário e uma fábula como Ph. App. 7, “Esopo e o escritor" pode revelar importantes pontos de contato:

Um sujeito recitou a Esopo sua má escrita, da qual, tolamente, muito se vangloria.

Daí, desejando saber o que o velho achava:

"Por acaso pareço mais a ti esplêndido nas palavras

ou há em mim uma confiança vã no talento?"

Esopo, acabrunhado pelo péssimo volume,

diz: "Eu aprecio que te elogies tão enérgico

pois o fato é que isso nunca virá a ti de outro" 23 .

A coexistência entre Esopo e algum tema relativo à crítica literária é, diante de todo o cenário desenhado, boa sugestão de algum aceno a Calímaco. Entretanto não se deve ignorar que a crítica aqui, diferentemente do que encontramos em Calímaco, é mais à disposição frente ao resultado da escrita do que propriamente a alguma estratégia de escrita. Esopo não comenta quaisquer opções criativas, não procura satirizar ou fazer comparações esdrúxulas entre o escritor e qualquer detalhe ou qualidade acerca daquilo que ele escreve. $O$ deboche está dirigido ao poeta, não apenas à poesia. E ao poeta, sobretudo, enquanto leitor da própria poesia e crítico da própria habilidade de escrever; como veremos à frente, o autoelogio de um mau poeta é também explorado no coliambo 22 de Catulo. A agressividade iâmbica está ausente para dar lugar a um comentário bem-humorado e elegante no qual Esopo procura informar o valor real da escrita a partir da recepção que ela terá entre outros: nenhuma; ou péssima, se alguma.

A criação Fedriana guarda consigo a cautela de um escritor que ainda não conhece a recepção que seu próprio uolumen terá; que calcula o risco da márecepção. No que a fábula poderia dizer de seu próprio autor, não há tanto aqui

\footnotetext{
${ }^{22}$ Ruth Scodel expande a alegoria e conjectura que cada uma das três personagens (Calímaco, seu opositor e o interventor, Sínon) poderia corresponder a um gênero literário. Sínon, o Iambo, teria interrompido uma briga entre a Elegia e o Hino, contando a fábula sobre a querela entre as duas plantas (SCODEL, 2011, p. 380).

${ }^{23}$ Tradução nossa de: Aesopo quidam scripta recitarat mala/ in quis inepte multum se iactauerat. /Scire ergo cupiens quidnam sentiret senex,/"Numquid sum uerbis uisus tibi superbior,/aut uana nobis ingeni fiducia est?"/Confectus ille pessimo uolumine:/'ego' inquit 'quod te laudas uehementer probo,/namque hoc ab alio nunquam continget tibi (FEDRO, Fab. App. 7, 1-8).
} 
a segurança do sucesso. Conhecer o livro ao qual essa fábula pertenceu originalmente permitiria, talvez, conjecturar melhor acerca do estatuto de sua obra entre seus primeiros leitores. Seus primeiros críticos, é possível, repetiriam o gesto simbólico de levar seu uolumen até Esopo para diagnosticar sua qualidade e concluir se o próprio Fedro se elogia em vão, como faz por exemplo no prólogo ao último livro da obra ( $P h$. 5. Pr), ou se de fato sua obra era de qualidade reputável. É também viável tratar a situação de modo mais circunscrito à fábula e estipular que a própria persona literária de Fedro, que não se declara aqui, poderia ocupar a posição alegórica de Esopo ou do escritor malsucedido. Interpretar a assunção de uma posição ou outra, obviamente, depende da avaliação que se faz da autoestima criativa que Fedro tem ao longo do seu fabulário e isso não é tarefa simples ${ }^{24}$.

\section{Fedro e Catulo}

Antes do grande popularizador do "iambo manco" em Roma, Catulo reformador da poesia romana sob a luz do legado de Calímaco ${ }^{25}$ - não há evidências textuais que poderiam ser cotejadas com a fábula fedriana de maneira ampla26. Catulo assina oito poemas em verso coliâmbico (Catul. 8, 22, 31, 37, 39, $44,59,60)$ que se relacionam variadamente com os iambógrafos anteriores e, eventualmente, podem ser categorizados segundo diferentes critérios.

Em sua tese de doutoramento Meter in Catullan invective: expectations and innovation, Michael Wheeler propõe um critério de organização para esse corpus coliâmbico de Catulo, que tem alguma utilidade para nosso estudo. $\mathrm{O}$ pesquisador divide os poemas em um primeiro grupo, marcado propriamente pela invectiva (poemas 37, 39, 59, 60) para expressar os tradicionais insultos virulentos especialmente a figuras politicamente irrelevantes, típicos da poesia

\footnotetext{
${ }^{24}$ A discussão é melhor desenvolvida em outras ocasiões. Patrick Glauthier em um artigo de 2009 procura argumentar no sentido de que a autoconsciência crítica de Fedro, registrada poeticamente em seu fabulário, tende - parodicamente ao próprio calimaquianismo - a desaguar em um senso de fracasso, de incapacidade de derrotar, mesmo que literariamente, a inveja dos críticos.

${ }^{25}$ Morgan acredita que a preferência de Calímaco pelo iambo tenha tido força sobre essa mesma escolha métrica de Catulo (MORGAN, 2010, p. 119). Forsyth declara que a constatação de uma influência significativa do iambo calimaquiano sobre a literatura latina é recente. Destaca que tanto Catulo quanto Calímaco realizam mudanças sofisticadas no epigrama helenístico (FORSYTH, 1977, p. 112). A importância de Hipônax para a obra de Catulo ainda que seja elusiva e possa se dever, mais uma vez, à intermediação de Calímaco está bem atestada (VINE, 2009, p. 213). Cumpre observar que, em seus ataques sérios mediados por coliambos, Catulo é mais hiponacteano do que Calímaco, em cuja poesia não encontraremos, por exemplo, a fixação de Hipônax por fluidos corporais, minimamente presente em Catul. 37.

${ }^{26}$ Podemos listar aqui as obras de Lévio (II-I a.C.), cujo único fragmento parece abordar controvérsia estilística; Gneu Mácio (I a.C.); Hélvio Cinna (I a.C.); Licínio Calvo (82-47 a.C.) o erudito Varrão (I a.c.) também conta com alguns versos coliâmbicos entre seus fragmentos de sátiras menipeias (fr. 55, 219, 293, 361, 374, 400, 569 Cèbe).
} 
de Hipônax ${ }^{27}$; esses portam as invectivas coliâmbicas de Catulo. O segundo grupo, o dos diagnósticos coliâmbicos (poemas 8, 22, 31, 44), normalmente se preocupa com a identificação e o tratamento de defeitos literários (WHEELER, 2015, p. 65). O comentador também defende que, nos poemas diagnósticos, Catulo retoma duas características típicas de Hipônax: a crítica artística (representada em Hipônax pelo seu antagonismo frente a Búpalo, Athenis e Mimnes) ${ }^{28}$ e a queixa médica ${ }^{29}$ (WHEELER, 2015, p. 65).

Tematicamente, o segundo grupo nos remete a um traço saliente na poesia coliâmbica de Calímaco e é justamente no poema 22 que encontramos a única alusão a uma fábula esópica em toda a produção poética de Catulo. Como relembra Watson, Catulo segue nesse poema a opção fixa calimaquiana de retomar a poesia de Hipônax renunciando à sua selvageria (o que nem sempre ocorre em outros coliambos do poeta latino) (WATSON, 1990, p. 27n).

Catul. 22 é um poema coliâmbico dirigido a um certo Varo, acerca de um poeta chamado Sufeno. Catulo o apresenta por partes. Primeiro, algo de sua personalidade, do seu modo de ser é informado ao leitor, no segundo verso: atraente (uenustus), gracioso (dicax) e polido (urbanus). Tão positivo perfil é imediatamente contraposto ao poeta, ser de qualidades diferentes, terríveis. A estas, a voz poética de Catulo dedica o intervalo do verso terceiro ao décimo nono. Tal como Horácio apontará em seu próprio precursor Lucílio ${ }^{30}$, a voz poética de Catulo pensa que seu colega de ofício é verborrágico ([...] facit plurimos uersus - v. 3 ) e de desmesurada produtividade (Puto esse illi milia aut decem aut plura/ praescripta [...] - v. 4-5). Os versos 5-8 ainda buscam informar o requinte instrumental do poeta, que utiliza material novo (nouei libri/nouei umbilici - v. 67) e de qualidade pertinente a uma publicação luxuosa ([...]lora rubra membranae,/ derecta plumbo et pumice omnia aequata. - v. 7-8). Isso tudo para - a hostilidade de Catulo desponta - escrever versos como quem abre fossas ou apascenta bodes (Suffenus unus caprimulgus aut fossor/ rursus videtur [...] - v. 10-11), dada a sua

\footnotetext{
${ }^{27} 0$ que é contrastado por Wheeler com seus poemas em trímetro iâmbico, Catulo 29 e 52, que são abertamente políticos. É tentador, embora elusivo, associar o coliambo a Hipônax pelo que ele tem de pouco politicamente engajado e o trímetro iâmbico a Arquíloco e Semônides pelo seu papel de "vigilância" moral em uma comunidade. Esta é, contudo, a opção associativa do comentador (WHEELER, 2015, p. 65).

${ }^{28} \mathrm{O}$ argumento é interessante por conectar os três coliambógrafos comentados neste artigo a um mesmo recurso temático. Entretanto, como salienta o crítico, Catulo, ao contrário de Hipônax, não tece críticas a obras de artes visuais. Do mesmo modo, os fragmentos de Hipônax não registram críticas a obras literárias. Hipônax tece críticas a Mimnes (Hippon. 28 West) por representar em navios serpentes olhando para a direção errada.

${ }^{29}$ Alguns fragmentos de Hipônax abordam queixas de saúde individual, como as menções ao resfriado, nos fragmentos 34-59 West; ou coletiva, caso das menções à tradição do phármakos (bode espiatório) nos fragmentos 5-10, 104 e 128W. Catul. 44 é invocado por Vine (2009) por apresentar um elemento lexical (frigus - v.20) comparável tematicamente com o que ocorre em Hipônax (rhígeos - Hippon. 34 West).

${ }^{30}$ Cf. Hor. Sat. I.4, 6-13; também encontraremos críticas à verbosidade em Catul. 36,1, em que os Annales do autor Volusius são chamados de cacata charta.
} 
irregularidade. Como relembra Shapiro, a oposição que ocorre imediatamente é à própria obra de Catulo, descrita como um libellus elegante (lepidus - v. 1) e polido (expolitus - v. 2) no primeiro de seus poemas. A recusa à concisão e ao rigor criativo afronta os preceitos calimaquianos dos quais Catulo é um dos primeiros defensores romanos. (SHAPIRO, 2011, p. 25).

A perplexidade da voz do poeta parece, então, circundar o contraste, difícil de se explicar (Hoc quid putemus esse?[...] - v. 12), de um homem fino e sofisticado ser um poeta mais grosseiro do que o próprio campo ([...] infacetior rure - v. 14) e a ponto de se regozijar e se admirar com sua própria poesia (tam gaudet in se tamquam se ipse miratur - v. 17). No décimo oitavo verso, todavia, a voz poética de Catulo muda bruscamente sua direção e se volta reflexivamente para uma universalização depreensível do quadro recém-pintado de Sufeno:

Decerto falhamos todos no mesmo, e não há ninguém em quem não possas ver, em alguma coisa, um Sufeno. A cada um se impõe seu próprio erro; mas não vemos o alforje que está sobre nossas costas. ${ }^{31}$

Como adequadamente avalia Susan Shapiro, Catulo transforma o que estava para se agravar como uma ofensa ad hominem em uma crítica da natureza humana; universal, portanto (SHAPIRO, 2011, p. 27). Se seguimos a interpretação de Thomson de que nimirum provavelmente inicia a resposta à pergunta do verso 12 (supracitada), a conclusão natural é a de que não somos muito diferentes de Sufeno; apenas criticamos os outros sem nos dar conta do que é passível de crítica em nós, como os dois versos finais apresentam em alusão uma fábula etiológica encontrada em Fedro ( $P h .4 .10)$ e nos coliambos de Bábrio, além de aludida por Horácio (Ars Poetica, v. 299) e pelo satírico Pérsio (4.24) 32. (THOMSON, 1997, p. 262).

A fábula em Fedro não se estende por muito mais do que os dois versos catulianos; registramos ela integralmente para, em seguida, uma pequena observação:

Júpiter pôs sobre nós dois alforjes;

um repleto de nossos próprios vícios deixou sobre as costas,

o lotado com os alheios pendurou frente ao peito.

Por isso não podemos ver nossos males;

\footnotetext{
31 Tradução nossa a partir de: Nimirum idem omnes fallimur, neque est quisquam/ quem non in aliqua re uidere Suffenum/ possis. Suus cuique attributus est error;/ sed non uidemus manticae quod in tergo est" (CATULO, 22, 18 -21).

320 desfecho moralizante resultante de uma caminhada crítica que parte do particular em direção ao universal parece a razão pela qual Thomson defende que, neste poema, a voz poética de Catulo é satírica (THOMSON, 1997, p. 258).
} 
Não há indicadores claros de que o poema de Catulo tenha servido de modelo a Fedro, ou de que Fedro o tivesse, também, em mente. A esse respeito, Patrick Glauthier acredita que a versão fedriana pode não ter se inspirado em nenhuma das versões romanas anteriores, mas não desenvolve essa opinião (GLAUTHIER, 2009, p. 265n).

Chama-nos atenção a conclusão do poema, em que se registra um destinatário implícito da crítica fabular: os censores, ou melhor, a hipocrisia dos censores. A censura (o psógos) tem um papel fundamental na poesia iâmbica arcaica, sendo um traço bem identificado desde Arquíloco e sua vituperação a Licambes ${ }^{34}$. Uma fábula como essa não apenas se desalinha com uma postura poética comum aos iambógrafos arcaicos - como já faz Calímaco - mas também se impõe criticamente contra essa postura que, por sua vez, será representada justamente pelo uso da invectiva pessoal, ausente da maioria de seus poemas e, quando presente, branda, dirigida a questões literárias.

O uso da fábula em Catulo, como instrumento de crítica literária, segundo Krostenko se distancia muito do que é usual para o poeta, por transcender o costumeiro grupo lexical que Catulo emprega como termômetro ético e estético dos seus invectivados (ou diagnosticados). Termos como os já conhecidos lepidus (elegante), uenustus (atraente), bellus (agradável), facetus (espirituoso) são empregados em diversas ocasiões na poesia de Catulo ${ }^{35}$ (KROSTENKO, 2007, p. 224). Pode-se reivindicar que eles sejam passíveis de alguma ambiguidade, que possam participar de outros tipos de caracterização ${ }^{36}$, para além da estilística como encontramos no poema em questão -, mas o escopo da sua aplicabilidade, em Catulo, é sempre individual. A fim de expressar uma crítica coletiva, Catulo deixa de lado o sistema de valores performado por esse léxico e recorre à fábula, um instrumento retórico também recomendado pela tratadística republicana (Retórica a Herênio, 4.24).

Catulo obtém um interessante efeito ao posicionar a alusão à fábula ao final do seu poema pois, se a crítica ao comportamento já garante universalidade

\footnotetext{
${ }^{33}$ Tradução nossa a partir de: Peras imposuit Iuppiter nobis duas;/Propriis repletam uitiis post tergum dedit,/Alienis ante pectus suspendit grauem./Hac re uidere nostra mala non possumus;/Alii simul delinquunt censores sumus.

${ }^{34}$ Ao que nos indica Brown, ao menos desde Píndaro (Píticas, 2.54-56), Arquíloco é reconhecido como o paradigmático psogerós (caluniador) (BROWN, 1997, p. 49).

${ }^{35}$ Encontramos esses termos, por exemplo, em Catul. 1 e Catul. 12, em que eles descrevem o tipo de poesia preferido por Catulo. Tais termos são encontrados também na crítica retórica do período republicano tardio e poderiam ser empregados para a descrição da prática de oradores e da qualidade de discursos. Cf. Cic., De Or., 1.17; 1.32; 2.251 e Ret. Her. 4.16. Brian Krostenko um levantamento mais amplo de ocorrências retóricas dos termos (KROSTENKO, 2007, p. 220).

${ }^{36}$ Krostenko defende que Catulo explora ideais eróticos, poéticos e sociais a partir do uso desses termos (KROSTENKO, 2007, p. 215).
} 
à mensagem, a alusão à fábula confere ainda um tom gnômico ao poema 22, e a impressão que persiste, por fim, é a de que os dois versos finais funcionam como uma espécie de epimítio a todo o conteúdo do poema. Sinteticamente, Catulo parece empregar, de modo discreto, a alusão à fábula como epimítio - isto é, um recurso interpretativo e conclusivo do próprio gênero fabular - para encerrar seu poema ${ }^{37}$.

A fábula ao fim do poema sugere algum apaziguamento, mas pode ocultar uma farpa sutil contra Sufeno. Esse último, brando ataque, não se identifica com a mensagem em si, mas com o que ela pode representar retoricamente. É difícil conhecer a disposição real que Catulo cultivava frente ao gênero fabular uma vez que seu uso é isolado em todo o cancioneiro. A fábula latina anterior a Catulo é pouco representativa e o fato de não ser amplamente empregada em contextos oratórios, apesar de ser retoricamente recomendada, não traz muita segurança argumentativa. De um lado, pode ser que apenas haja essa repentina mudança do ethos catuliano, de um jovem poeta elegante e moderno para um velho caridoso que divide sua sabedoria proverbial - imagem esta sugerida por Krostenko - a fim de redirecionar o alvo crítico (KROSTENKO, 2007, p. 224). De outro, talvez Catulo esteja somando o seu poema aos exemplos de associação entre a fábula e a baixa valoração social que abundam em toda a literatura grecoromana ${ }^{38}$. Essa precisa analogia tornaria conveniente contar uma fábula como corolário à descrição de um homem que escreve como um abridor de fossas ou um cuidador de bodes, tal como, à guisa de exemplo, é conveniente ao Menênio Agripa de Tito Lívio discursar de "modo rústico e grosseiro" à plebe que deixara Roma em secessão ${ }^{39}$. Menênio Agripa, na ocasião, narra uma fábula à plebe pelo que ela é. Catulo, por sua vez, descreve um homem com uma fábula pelo que ele escreve. Essa possibilidade reforçaria a opinião de Watson, retomada por Wheeler, de que a rusticidade de Sufeno se destacaria no poema; isso, apesar de qualquer generalização pedagógica ou tentativa de conciliação (WATSON, 1990; WHEELER, 2015, p.94).

Regozijar-se por uma característica não possuída, o autoengano do pretensioso, é um tema que atravessa a poesia de Catulo ${ }^{40}$. Do mesmo modo, ainda que por razões de natureza passível de discussão, o tema é bem-marcado na obra de Fedro, em que a fábula é sempre intolerante à artificialidade que encobre a verdade. O poeta autoiludido é encontrado especificamente no poema Ph. App. 7, discutido na seção anterior, mas não faltam outros exemplos de

\footnotetext{
${ }^{37}$ Watson tange essa reflexão sem desenvolvê-la, mas chama atenção para o fato de que a própria escolha temática da fábula remete à rusticidade, já que os sacos (manticae/péras) mencionados na fábula são carregados sobretudo por camponeses. (WATSON, 1990, p. 15)

${ }^{38}$ Sobre fábula e subalternidade, cf. JORDAN, 2013.

${ }^{39}$ Liv. Ab Urbe Condita, II. 32.5-12.

${ }^{40}$ Shapiro identifica o tema nos poemas 12, 22, 39, 42 e 84. Catulo 22 e 39 são coliâmbicos. (SHAPIRO, 2011, p. 23).
} 
vaidade desmesurada. Já no primeiro livro de seu fabulário, cinco das 31 fábulas são dedicadas ao assunto. Ao longo de toda a coleção, Fedro trata do tema em dez fábulas ${ }^{41}$.

Algumas entre essas fábulas, que resumiremos a título de exemplo, portam um conteúdo que sugere maior sensibilidade crítica à estética. Assim, $P h$. 1.3 conta a história de uma gralha que renuncia sua natureza, cata penas de pavão para se enfeitar e se juntar a esta espécie de pássaros; desprezada, ela tenta voltar ao seu bando original, mas é, também, rejeitada. Essa fábula foi, inclusive, aproveitada por Horácio (Ep. 1.3, 18-20) como instrumento de crítica literária. Na fábula 5.7, a vaidade diante de uma habilidade artística rende à protagonista, de nome Príncipe, uma confusão humilhante quando, logo após sua própria apresentação, o público ovaciona o antigo imperador Otávio Augusto.

Em três fábulas específicas há ambientação de personagens cujo som da própria voz é objeto central da crítica tecida. Primeiramente, em Ph.1.11 um leão chama um burro para ajudá-lo na caça, ilude-o, convencendo-o de que possuía uma voz aterrorizante apenas para se aproveitar dos sustos imprevisíveis que ele causava, escondido em folhagens, às presas que passavam. Em Ph. 1.13, um corvo perde o pedaço de queijo para uma raposa após receber um (falso) elogio e começar a exibir seu canto. Por fim, em Ph. 3.16, uma coruja se irrita com o canto de uma cigarra e, sem sucesso ao pedir que esta se silencie, convida-a para um banquete dizendo que suas melodias não a deixavam dormir porque pareciam acompanhadas pela cítara de Apolo. Sentindo-se elogiada, a cigarra aceita o convite da coruja e acaba sendo morta.

Não havendo uma chave para uma leitura profunda das alegorias subjacentes às fábulas, só resta conjecturar acerca das possíveis identidades sociais das personagens fabulares. Há uma possibilidade, firmada por um topos iniciado na mais antiga fábula grega - "O Falcão e o Rouxinol", presente nos Trabalhos e os Dias de Hesíodo - de que animais destacados pelos seus sons canoros - sobretudo pássaros - sirvam de metáforas para poetas (STEINER, 2007). O grupo de animais cujos sons são criticados (ou falsamente elogiados) é ampliado para incluir a cigarra que, antes, já havia sido incluída em um poema não iâmbico de Calímaco (Aetia, fr. 1) com essa mesma função que reivindicamos. Incluir o burro - destacado na fábula pela qualidade particular de ser falsamente elogiado quanto à voz assustadora - depende de se considerar que Fedro se refere a uma forma particular de poesia em que a beleza e a musicalidade não são as qualidades mais em evidência; caso, por exemplo, da poesia iâmbica. Mas se aprofundar nessa interpretação é tarefa que não cabe a este estudo.

${ }^{41}$ Ph. $1.3 ; 1.11 ; 1.12 ; 1.13 ; 1.24 ; 2.7 ; 3.17 ; 4.22 ; 5.7 ;$ App.13. 


\section{Considerações finais}

Os estudos interessados em analisar a poesia do fabulista Fedro (I d.C.) não costumam se deter sobre as condicionantes que teriam levado o primeiro antologista de fábulas latinas a polir sua matéria em versos senários iâmbicos. Ainda que este não tenha sido o propósito do presente trabalho, a delimitação do tema nos conduz à reflexão sobre o lugar de Fedro dentro do que poderíamos designar uma "tradição iâmbica"; as comparações com Catulo, sob esse pretexto, são, portanto, essenciais.

As características aventadas e contrastadas podem não ser exclusivas de um ramo coliâmbico da tradição de poetas que escrevem em verso iâmbico: ora são muito difundidas para se lhes associar um gênero, caso da misoginia; ora têm alguma flutuação de presença e/ou intensidade entre os autores e épocas, como é o que acontece com a linguagem virulenta, por mais que alguma forma de invectiva ou crítica ao outro - sendo ele um indivíduo identificado, um anônimo ou um categoria inespecífica de indivíduos - seja costumeira. Deve-se reconhecer: o corpus é pequeno para um levantamento de características; não tanto pelo estado fragmentário de alguns de seus autores, mas pelo fato de que há uma série de figuras que poderiam ser examinadas no conjunto: outros coliâmbicos helenísticos, ou autores posteriores, como o fabulista Bábrio e o poeta Marcial, são alguns exemplos. Apenas uma percepção com essa amplitude permitiria descrever com precisão um possível ethos da poesia coliâmbica e compreender o dinamismo diacrônico de suas características.

A escolha de Fedro, um poeta de um outro ramo da tradição iâmbica, como foco investigativo deixa margem para comparações inconclusivas, pois as características encontradas na poesia dos quatro autores tratados poderiam, na verdade, facilmente ser típicas da tradição iâmbica como um todo e não exclusivas de um ramo coliâmbico com o qual o fabulista, um poeta de derivação contígua, procurou estabelecer um diálogo. Além da própria formulação métrica, a forma mais segura de aceno para um ramo coliâmbico da tradição iâmbica seria uma alusão ao seu provável prôtos heuretếs: Hipônax. Fedro não lança mão de nenhuma dessas duas estratégias, enquanto Catulo provavelmente empreende as duas.

Entretanto, o enfoque no eixo Catulo-Fedro da poesia iâmbica romana torna necessária certa especificação do olhar que se lança sobre a suposta tradição reivindicada. Afinal, com os débitos pós-catulianos à poesia de Calímaco, inclusive no uso que Catulo faz da poesia iâmbica, é razoável considerar que há, em alguma medida, um deslocamento de Hipônax para Calímaco na constituição identitária da poesia coliâmbica. É, portanto, mais cabível a particularização de 
uma "poesia coliâmbica pós-calimaquiana" que teria, por sua vez, características mais nítidas dentro do corpus explorado.

Se Catulo é herdeiro, por excelência, dessa subtradição coliâmbica, desse recorte que se identifica ao mesmo tempo com um período da história literária clássica e com a atividade de um autor, Fedro procura, ao menos, se comunicar com ela. Este trabalho, enfim, chama atenção para um componente dessa comunicação que possivelmente perfaz uma característica dessa subtradição coliâmbica: o emprego da fábula como plataforma poética para a crítica estética e, em especial, a polêmica literária. Uma vez que os fragmentos de Hipônax não permitem constituir um cenário robusto para se detectar essa característica também no período arcaico da poesia grega, é minimamente adequado percebêla como uma característica bem demarcada a partir da poesia coliâmbica de Calímaco e que tem sólida representação em Catulo e Fedro.

\section{REFERÊNCIAS}

ACOSTA-HUGHES, Benjamin. Polyeideia: The Iambi of Callimachus and the Archaic Iambic Tradition. Berkeley: University of California Press, 2002, 351p.

ADRADOS, Francisco. Historia de la fábula Greco-Latina. Tomo I. Madrid: Editorial de la Universidad Complutense, 1979, 726 p.

ALVAREZ, Beethoven. Senário Iâmbico em Plauto: Efeitos em 'Persa' e 'Estico'. 2016. Tese (Doutorado em Linguística). Instituto de Estudos da Linguagem, Universidade Estadual de Campinas, 2016.

BROWN, Christopher. Iambos. In: GERBER, Douglas. A Companion to Greek Lyric Poets. Leiden: Brill, 1997. p. 11-89.

CALLIMACHUS; MUSAEUS. Fragments; Hero and Laender. Edited and Translated by C.A. Trypanis, Thomas Gelzer, Cedric Whitman. Cambridge: Harvard University Press, 1975.

CATULLUS. The poems of Catullus: a bilingual edition. Translated with commentary, by Peter Green. Berkeley: University of California Press, 2005.

CATULLUS; THOMSON, Douglas Ferguson Scott. Catullus. Edited with a textual and interpretative commentary by D.F.S. Thomson. Toronto: University of Toronto Press, 1997. 
CAREY. Chris. Iambos. In: BUNDELMANN, F. The Cambridge Companion to Greek Lyric. Cambridge: Cambridge University Press, 2009, p. 149-168.

FORSYTH, Phyllis. Catullus and the Iambi of Callimachus. Mosaic: A Journal for the Interdisciplinary Study of Literature, Winnipeg, vol. 10, n. 4, 1977, p. 111-116. Disponível em: http:/ / www.jstor.org/stable/24780304. Acesso em: 21 de set. de 2020.

FREITAS, Gustavo. Sobre o Estilo de Demétrio: um olhar crítico sobre a Literatura Grega (Tradução e estudo introdutório do tratado). Dissertação (Mestrado em Estudos Literários). Faculdade de Letras, Universidade Federal de Minas Gerais, 2011.

GLAUTHIER, Patrick. Phaedrus, Callimachus and the Recusatio to Success. Classical Antiquity, vol.28, n.2, 2009, p. 248-278. Disponível em: https://www.jstor.org/stable/10.1525/ca.2009.28.2.248. Acesso em 16 de abr. de 2021.

HORACE. Satires. Epistles. The Art of Poetry. Translated by H. Rouston Fairclough. Cambridge: Harvard University Press, 1926.

JORDAN, Cara Tess. Voicing Power through the Other: Elite Apropriations of fable in the 1st -3rd Centuries CE. PhD Thesis. Toronto: University of Toronto, 2013.

JUVENAL; PERSIUS. Satires. Edited and Translated by Susanna Morton Braund. Cambridge: Harvard University Press, 2004.

KROSTENKO, Brian. Catullus and Elite Republican Social Discourse. In; SKINNER, M. A Companion to Catullus. Malden: Blackwell Publishing, 2007, p. 212-233.

MORGAN, Llewelyn. Musa Pedestris: Metre and Meaning in Roman Verse. Oxford: Oxford University Press, 2010.

PERRY, Ben E. Babrius and Phaedrus: Fables. London: Harvard University Press, 1965.

PUTNAM, Michael. Catullus, 22.13. Hermes, Stuttgart, 96 Bd., H.4, 1968, p. 552558. 
RUSSO, Alessandro. Iambic Presences in Ennius' saturae. In: ALONI, A. et al. Iambic Ideas: Essays on a poetic tradition from Archaic Greece to the Late Roman Empire. Lanham: Rowman and Littlefield Publishers, 2001, p. 99 - 115.

SCODEL, Ruth. Callimachus and Fable. In: ACOSTA-HUGHES, B. et al. Brill`s Companion to Callimachus. Leiden: Brill, 2011. p. 368-384.

SHAPIRO, Susan O. The Mirror of Catullus: Poems 12, 22, 39, 41, 42 and 84. Syllecta Classica, vol. 22, p. 21-37, 2011. Disponível em: https://muse.jhu.edu/article/476800. Acesso em 16 de abr. de 2021.

STEINER, Deborah. Feathers Flying: Avian Poetics in Hesiod, Pindar, and Callimachus. The American Journal of Philology, v. 128, n. 2, p. 177-208, 2007. Disponível em: https://www.jstor.org/stable/4496958. Acesso em 16 de abr. de 2021.

TITTI-LIVI. A b Urbe Condita. Tomus I. Libri I-V. Recognouerunt et Adnotatione Critica instruxerunt Robertus Seymour Conway et Carolus Flamtead Walters. Londini: E Typographeo Clarendoniano, 1960.

VINE, Brent. A Hipponactean Echo in Catullus (Frigus, 44.20). Classical Philology, v.104, n. 2 2009, p. 213-216. Disponível em: https:/ / www.jstor.org/stable/10.1086/605344. Acesso em 16 de abr. de 2021.

WATSON, Lindsay. Rustic Suffenus (Catullus 22) and Literary Rusticity. In: CAIRNS, Francis et al. Papers of the Leeds International Latin Seminar. v. 6. Leeds: Francis Cairns, 1990, p. 13-33.

WHEELER, Michael. Meter in Catullan Invective: Expectations and Innovations. PhD Thesis. Boston: Boston University, 2015. 